\title{
Promosi Kesehatan ibu dan Anak pada ibu-ibu Bayi/Balita di RW 18 Kelurahan Jayawaras Kabupaten Garut
}

\author{
Umar Sumarna ${ }^{1}$, Nina Sumarni ${ }^{2}$, Udin Rosidin ${ }^{3}$ \\ ${ }^{1,2,3}$ Universitas Padjadjaran, Jl. Raya Bandung Sumedang KM.21, Hegarmanah, Jatinangor, \\ Kabupaten Sumedang, Jawa Barat 45363 \\ Email: umar.sumarna@unpad.ac.id ${ }^{1 *}$
}

\begin{abstract}
ABSTRAK
Kesehatan ibu dan anak merupakan salah satu faktor yang penting untuk menentukan derajat kesehatan masyarakat. Seperti yang terjadi di Indonesia, tingginya angka kematian ibu dan anak akan berdampak pada menurunnya tingkat kesehatan masyarakat. Hal ini terjadi karena rendahnya pengetahuan ibu tentang pemeliharaan kesehatan ibu dan anak. Untuk itu, tim pengabdian bertujuan menekan peningkatan kasus tersebut dengan cara memberikan promosi kesehatan terhadap salah satu kelompok masyarakat di Indonesia, yaitu ibu-ibu bayi dan balita di RW 18 Kelurahan Jayawaras Kabupaten Garut. Metode yang digunakan adalah ceramah, tanya jawab, dan demonstrasi. Hasil dari pendidikan kesehatan menunjukkan adanya peningkatan pengetahuan ibu-ibu tentang pemeliharaan kesehatan ibu dan anak. Peningkatan pengetahuan peserta kegiatan ditunjukkan dengan hasil pretes dengan rata-rata nilai 69,64 menjadi 84,64 pada nilai postes, nilai minimal 50 pada pretes menjadi 60 pada postes, dan nilai maksimal 80 pada pretes menjadi 100 pada postes. Hasil ini membuktikan bahwa ibu-ibu di RW 18 sangat antusias dalam mengikuti pendidikan kesehatan tersebut dikarenakan mereka merasa membutuhkan.
\end{abstract}

Kata Kunci: Promosi Kesehatan; Tingkat Pengetahuan; Angka Kematian Ibu/Anak

\begin{abstract}
Maternal and infant/toddler health is an important factor and greatly determines the degree of public health. As happened in Indonesia, caused by the height of maternal and infant/toddler mortality rate impacts a low degree of public health. This happens caused by the low knowledge of ma about maternal maintaining maternal and infant/toddler health. For this reason, the community dedication team aimed to suppress the increase in cases by providing health promotion to one of the community groups in Indonesia, namely maternal in RW 18 Jayawaras Village Garut Regency. The methods used were lectures, discussion, and demonstrations. The results of health promotion indicated an increase in maternal knowledge about maintaining maternal and infant/toddler health. The increase in knowledge of the participants was shown by the results of pre-tests with an average score of 69.64 to 84.64 on post-test values, a minimum value of 50 on the pre-test to 60, and a maximum value of 80 on the pre-test to 100 in post-test. These results prove that the maternal in $R W 18$ Jayawaras village were very enthusiastic in participating in the health promotion because they felt they needed it.
\end{abstract}

Keywords: Health Promotion, Level of Knowledge, Maternal / Infant Mortality

\section{PENDAHULUAN}

Undang-Undang Nomor 35 tahun 2014 tentang Perlindungan Anak (Undang-Undang RI, 2014) mengungkapkan bahwa setiap anak memiliki hak hidup dan tumbuh-kembang 
seoptimal mungkin. Demikian juga Undang-Undang Perlindungan Anak juga menitikberatkan bahwa seluruh elemen, baik pemerintah, masyarakat hingga keluarga memiliki tanggung jawab terhadap perlindungan kehidupan anak secara komprehensif sejak dalam kandungan.

Untuk menjamin kelangsungan hidup dan tumbuh kembang anak, maka menurut Undang-Undang Nomor 36 Tahun 2009 Tentang Kesehatan (Undang-Undang RI, 2009), "bahwa kebutuhan dasar anak harus dipenuhi. Penyelenggaraan perlindungan anak di bidang kesehatan direalisasikan dengan cara melaksanakan pemantauan kesehatan anak dimulai sejak bayi berada dalam kandungan hingga usia remaja”. Program ini bertujuan memelihara dan meningkatkan kesehatan anak sesuai tumbuh kembangnya. Hal ini dikategorikan sangat penting mengingat bahwa anak merupakan sumber daya pembangunan bangsa di masa yang akan datang.

Salah satu kelompok masyarakat yang rentan terhadap penyakit dan masalah kesehatan lainnya adalah Ibu matrenal (ibu hamil, ibu bersalin, ibu nifas) dan bayi (usia 01 tahun). Terbukti bahwa angka kematian kedua kelompok selalu lebih tinggi dari kelompok lainnya, termasuk di Indonesia yang disebakan oleh kekurangan gizi. Berdasarkan hal itu, Kemenkes RI (2015) telah menetapkan sasaran pokok Rencana Pembangunan Jangka Menengah Nasional (RPJMN) tahun 2015 - 2019 yang mendapat urutan paling atas dalam peningkatan status gizi dan pemeliharaan kesehatan ibu dan anak.

Seperti yang tercermin pada RPJMN, pelayanan kesehatan yang direncanakan lebih fokus pada upaya agar bayi dapat lahir dengan selamat dan kelangsungan hidup anak (child survival). Walaupun tidak menjadi fokus perhatian dalam RPJMD, sesungguhnya ada masalah lain yang tidak dapat diabaikan terkait dengan kesehatan anak, yaitu bagaimana seorang anak mencapai tumbuh kembang anak secara optimal.

Salah satu upaya pemerintah melalui Menteri Kesehatan untuk meningkatkan kesehatan ibu dan tumbuh kembang anak adalah dengan memberdayakan peran serta masyarakat. Upaya itu dilakukan dimulai dengan didirikannya fasilitas kesehatan masyarakat berupa Pos Pelayanan Terpadu (Posyandu) di lingkungan masyarakat desa, baik tingkat RW maupun RT. Adapun aktiitas posyandu tersebut, selain untuk memantau tumbuh kembang anak, posyandu dikembangkan juga untuk melayani kebutuhan masalah kesehatan lainnya yang sering muncul di masyarakat, seperti pemeriksaan ibu hamil, penanggulangan diare, pemeliharaan kesehatan lingkungan dan lain-lain.

Dalam penyelenggaraannya, pengembangan posyandu membutuhkan partisipasi masyarakat yang tinggi, baik dari kader-kadernya maupun keluarga-keluarga yang 
memanfaatkan fasilitas kesehatan ini, seperti ibu-ibu yang memiliki anak balita agar dapat memantau tumbuh kembang anak balita melalui berat badannya setiap bulan (Kemenkes RI, 2012). Menilik keadaan seperti itu maka Kemenkes RI (2011) menyatakan bahwa revitalisasi posyandu harus ditingkatkan agar kebutuhan pelayanan kesehatan pada masyarakat terpenuhi secara optimal. Hal itu dapat terjadi bersamaan dengan meningkatnya pengetahuan dan keterampilan serta dedikasi para kader terhadap kelangsungan penyelenggraan posyandu.

Dalam laporannya, Dinkes Prop Jabar (2015) menyatakan bahwa AKI dan AKB di Jawa Barat cukup tinggi, bahkan menempati tempat teratas sebagai penyumbang AKI di Indonesia. Kasus kematian ibu hamil, ibu bersalin, dan ibu nifas meningkat cukup signifikan, yaitu 748 kasus pada tahun 2014 meningkat menjadi 823 kasus pada tahun 2015. Begitu juga pada bayi baru lahir, dari 3098 kasus pada tahun 2014 meningkat menjadi 3369 kasus pada tahun 2015. Jadi bisa dikatakan bahwa setiap hari di Jawa Barat pada tahun 2015 rata-rata kehilangan 2 Ibu dan 9 bayi akibat kematian tersebut.

Sebagai salah satu kabupaten di Propinsi Jawa Barat juga memiliki data AKI dan AKB yang cukup mengkhawatirkan, yang tentunya merupakan penyumbang AKI dan AKB yang tinggi di Jawa Barat. Tercatat dalam Renstra Dinkes Kab. Garut (2015) bahwa adanya peningkatan AKI di tahun 2014 sebanyak 45 kasus menjadi 74 kasus di tahun 2015 dan AKB di tahun 2014 sebanyak 278 kasus menjadi 333 kasus di tahun 2015. Menurut Wakil Bupati Garut, Kabupaten Garut menempati urutan ketiga tentang tingginya AKI dan AKB di Jawa Barat.

Ada banyak faktor yang mungkin sangat berpengaruh terhadap tingginya kasus kematian ibu dan bayi di Kabupaten Garut. Hal ini berhubungan dengan kondisi geografis Kabupaten Garut yang sangat luas, maka kasus kematian tersebut sering terjadi akibat keterlambatan penanganan pasien di pelayanan fasilitas kesehatan (RS dan Puskesmas). Keterlambatan tersebut pada umumnya disebabkan keterlambatan dalam mendapat pertolongan, mendapat rujukan, dan mendapatkan pelayanan fasilitas kesehatan. Selain itu, faktor budaya dari sebagian masyarakat Garut yang masih mengupayakan pertolongan persalinannya di luar tenaga profesi kesehatan. Kondisi seperti ini tentunya merupakan tantangan tersendiri yang turut pula meningkatkan tingginya AKI dan AKB.

AKI dan AKB serta angka kekurangan gizi adalah merupakan faktor yang sangat mempengaruhi derajat kesehatan masyarakat. Untuk menanggulanginya perlu didukung oleh sumber daya serta teknologi yang memadai. Sementara Kabupaten Garut pada Tahun 2018 memiliki tenaga kesehatan sebanyak 4.394 orang yang tersebar di enam puluh tujuh 
(67) UPT Puskesmas dan Labkesda, serta di RSUD Dr. Slamet Garut, RS Guntur, RSUD Pameungpeuk, RS Nurhayati, RS Anisa Queen dan RS Intan Husada. Tenaga non kesehatan sebanyak 1.125 orang.

Bila melihat angka-angka diatas tampaknya cukup memadai, namun rupanya kedua faktor yang telah disebutkan di atas sangat besar pengaruhnya terhadap peningkatan AKI dan AKB di Kabupaten Garut. Hal ini menunjukkan bahwa masyarakat Kabupaten Garut khususnya ibu-ibu bayi dan balita membutuhkan promosi kesehatan. Menurut Nurmala dkk (2018), Promosi kesehatan adalah proses yang memungkinkan seseorang untuk mengontrol dan meningkatkan kesehatan.

Di RW 18 Kelurahan Jayawaras Kabupaten Garut yang memiliki 3 buah posyandu dan memiliki banyak ibu-ibu bayi dan balita dengan kebanyakan berpendidikan SD dan pada saat dilakukan survei lapangan masih banyak yang tidak memanfaatkan fasilitas kesehatan yang ada (puskesmas dan posyandu), serta ada beberapa diantara bayi dan balitanya menderita kurang gizi. Hasil penelitian Handayani (2017) menunjukkan bahwa ada pengaruh signifikan antara status gizi kurang dengan kejadian infeksi.

Sesuai dengan masalah yang ada di RW tersebut, maka tujuan pengabdian ini adalah untuk memberikan promosi kesehatan pada ibu-ibu bayi dan balita agar terjadi peningkatan pengetahuannya dalam pemeliharaan kesehatan ibu dan anak sehingga dapat menekan peningkatan AKI, AKB, dan status kurang gizi bagi anak di RW 18 Kelurahan Jayawaras Kabupaten Garut.

\section{METODE}

Kegiatan pengabdian dilaksanakan oleh tim yang terdiri dari 3 orang dosen keperawatan dari Universitas Padjadjaran dibantu oleh 5 orang mahasiswa profesi angkatan tahun 2020. Dilakukan pada ibu-ibu bayi dan balita sebagai sasaran penyuluhan sebanyak 28 orang. Kegiatan ini dihadiri juga oleh ketua RW 18, tokoh masyarakat, kaderkader kesehatan dan petugas lapangan dari Puskesmas Haurpanggung.

Kegiatan pengabdian ini dilakukan selama 3 hari, dari tanggal 10 s.d 12 Maret 2020, mulai dari kegiatan persiapan, penyusunan materi, dan pelaksanaan penyuluhan. Kegiatan persiapan yang dilakukan yaitu survei lokasi pelaksanaan kegiatan, mengidentifikasi masalah kesehatan, penetapan sasaran kegiatan, pembuatan proposal, serta persiapan tempat dan alat-alat. Dilanjutkan dengan penyusunan materi tentang pendidikan kesehatan ibu dan anak yang mencakup pengertian, jenis pelayanan, dan bentuk esensial pelayanan kesehatan yang harus diberikan pada ibu dan anak-anaknya yang masih bayi dan balita. 
Akhirnya pada hari terakhir penyuluhan dilakukan di kantor Kelurahan Jayawaras. Metode yang digunakan adalah ceramah berupa penyampaian materi tentang bagaiamana cara meningkatkan kesehatan ibu dan anak menurut ilmu kesehatan.. Sedangkan media yang digunakan adalah Laptop, flash disc, LCD dan proyektor. Sebelum dilakukan penyuluhan, terlebih dahulu dilakukan pretes untuk melihat pengetahuan awal dari sasaran penyuluhan. Kemudian dilakukan pula postes setelah kegiatan penyuluhan selesai, lalu hasilnya dibandingkan dengan hasil pretes untuk melihat sejauhmana keberhasilan kegiatan, yaitu peningkatan pengetahuan ibu-ibu tentang kesehatan ibu dan anak.

\section{HASIL, PEMBAHASAN, DAN DAMPAK}

Kegiatan pengabdian dilakukan untuk meningkatkan pengetahuan ibu-ibu bayi dan balita tentang pemeliharaan kesehatan bagi ibu dan anak. Ibu-ibu tampak menyimak semua informasi yang diberikan oleh tim pengabdian. Pada saat berlangsungnya pemberian materi, terjadi komunikasi dua arah, dan diskusi interaktif.

Sebelum dan sesudah materi penyuluhan diberikan, terlebih dahulu dilakukan pretest dan postest untuk mengetahui sejauhmana peningkatan pengetahuan sebelum dan sesudah kegiatan penyuluhan atau pendidikan kesehatan diberikan. Hasil pretes dan protes tersebut dapat ditinjau melalui tabel 1.

Tabel 1. Hasil Pretes dan Postes Ibu-ibu Bayi dan Balita

\begin{tabular}{ccccc}
\hline No & Pengetahuan & Mean & Min & Maks \\
\hline 1 & Pretes & 69,64 & 50 & 80 \\
2 & Postes & 84,64 & 60 & 100 \\
\hline
\end{tabular}

Tabel di atas menggambarkan bahwa nilai rata-rata peserta adalah 69,64 untuk pretes dan 84,64 untuk postes. Gambaran ini menunjukkan bahwa pendidikan kesehatan dari tim pengabdian meningkat sebesar 15 angka. Begitu pula nilai minimum pretest dari 50 menjadi 60 pada nilai postes (peningkatan 10 angka) dan nilai maksimum sebesar 80 menjadi 100 pada nilai postes (peningkatan 20 angka).

Menurut tokoh masyarakat setempat, ibu-ibu bayi dan balita di RW 18 belum pernah mendapat penjelasan dari petugas atau kader kesehatan disekitarnya dan kurangnya pergaulan dan tingkat pendidikan ibu yang rendah sehingga nilai pretes rata-ratanya rendah. Setelah dilakukan pendidikan kesehatan terjadi peningkatan yang ditunjukkan pada nilai rata-rata postes. Keragaman daya tangkap dari peserta juga dapat ditunjukan pada rentang nilai minimum dan maksimum baik pada nilai pretes maupun postes. 


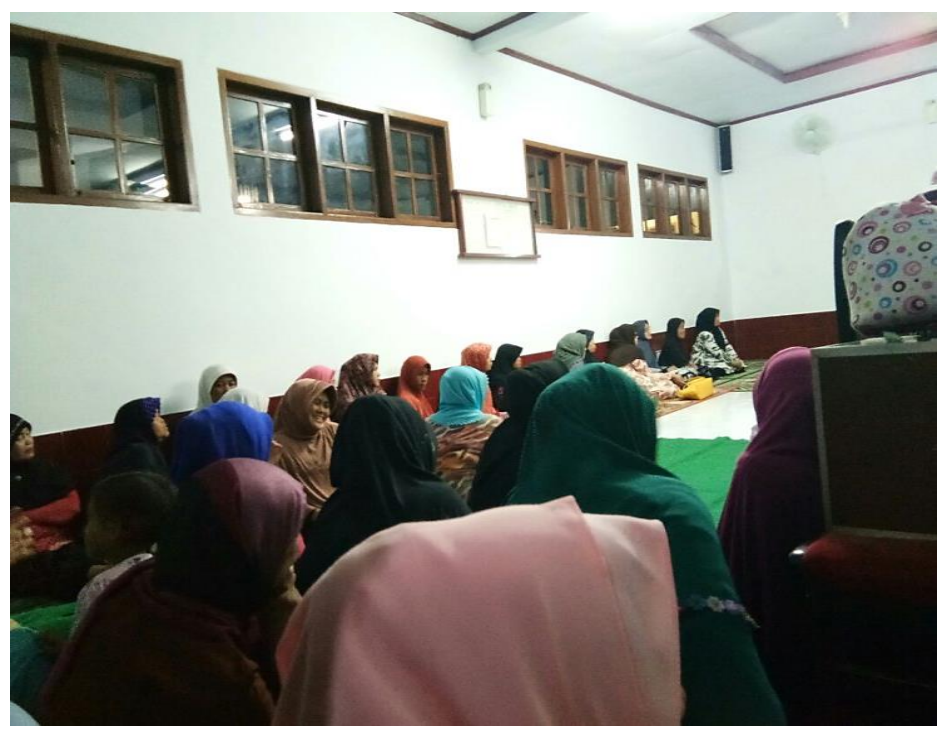

Gambar 2. Ibu-ibu bayi dan balita RW 18 sedang mengikuti kegiatan penyuluhan

Peningkatan ini terjadi karena pendidikan kesehatan yang diberikan dianggap merupakan kebutuhan bagi mereka. Terbukti pada saat pemberian materi ada 8 peserta yang bertanya dan minta penjelasan ulang, sehingga waktu kegiatan bertambah lama dari kegiatan yang sudah direncanakan. Penyuluhan juga dilakukan secara kekeluargaan, sehingga komunikasi antara penerima dan pemberi materi berjalan secara dua arah, suasananya sengaja dibuat santai tapi serius. Komunikasi tidak hanya mengacu pada isi, tetapi juga pada perasaan dan emosi ketika individu menyampaikan hubungan (Maulana, 2009).

Tingginya pengetahuan ibu-ibu tentang cara pemeliharaan kesehatan sangat bermanfaat baik untuk dirinya maupun untuk bayi dan balitanya. Kesehatan bayi dan balita sangat penting karena di usia ini seorang anak sedang menuju usia sekolah yang berhubungan prestasi belajarnya di kelak kemudian hari. Dalam Kristanti dan Sebtalesy (2021) dinyatakan bahwa proses belajar di masa depan pada anak usia sekolah dasar akan dipengaruhi oleh pertumbuhan dan perkembangannya di masa awal proses pembelajaran. Prestasi belajar dapat ditingkatkan salah satunya melalui peningkatan gizi di masa anakanak dan usia sekolah. Sementara di Indonesia AKI, AKB, dan prevalensi gizi kurang masih tinggi yang menunjukkan bahwa status kesehatan ibu dan anak di usia bayi dan balita jauh lebih rendah dari kelompok usia lainnya.

Suatu cara yang paling mudah dilakukan untuk mengetahui gambaran status gizi seseorang adalah pengukuran tinggi badan (Sefrina dan Elfandari, 2020). Sehingga dapat dilakukan oleh ibu-ibu sendiri di rumah, tanpa harus melibatkan petugas kesehatan. Dampak dari kekurangan gizi yang kronis bisa saja berdampak pada masalah kesehatan 
lain yang lebih serius, seperti yang dikatakan Andriani dan Wirjatmadi (2012), bahwa gizi kurang dapat menyebabkan kegagalan fungsi organ seperti organ pencernaan, organ endokrin jantung, dan ginjal.

Promosi kesehatan dari tim pengabdian adalah terjadinya peningkatan pengetahuan ibu-ibu bayi dan balita tentang cara-cara pemeliharaan kesehatan di RW 18 Kelurahan Jayawaras Kabupaten Garut. Berkat pengetahuan yang meningkat, maka perilaku ibu-ibu dalam memelihara kesehatannya menjadi lebih baik pula, sehingga dapat menekan AKI, AKB dan prevalensi gizi kurang. Peningkatan pengetahuan ibu-ibu bayi dan dan balita sesuai dengan kegiatan yang dilakukan oleh Angelina dkk (2019) bahwa pengetahuan peserta kegiatan penyuluhan akan meningkat setelah dilakukan pendidikan kesehatan.

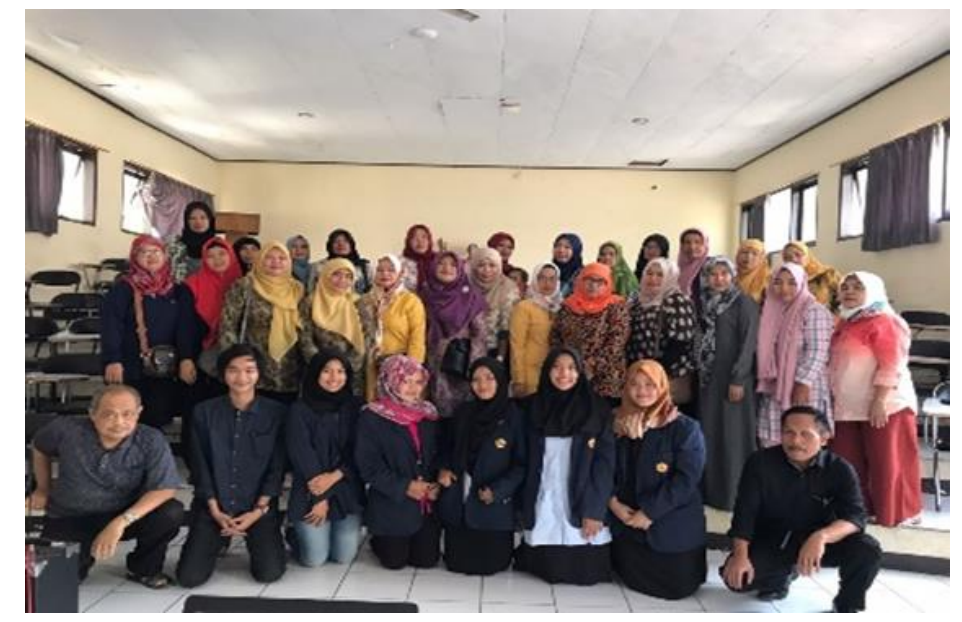

Gambar 2. Berfoto bersama di akhir kegiatan penyuluhan

\section{SIMPULAN}

Setelah dilakukan pendidikan kesehatan, maka terjadi peningkatan pengetahuan pada ibu-ibu bayi dan balita di RW 18 Kelurahan Jayawaras kab.Garut, yaitu dari pengetahuan awal dengan rata-rata nilai 69,64 menjadi 84,64.

Hal ini menjadi gambaran bahwa ibu-ibu di RW 18 mempunyai minat yang besar untuk memahami cara-cara pemeliharaan kesehatan yang harus diterapkan pada dirinya dan anak-anaknya terutama yang masih berada pada usia bayi dan balita. Ibu-ibu tersebut menyadari bahwa anak dalam usia tersebut masih rentan terhadap penyakit yang berpotensi kematian. Keadaan tersebut akan menjadi potensi untuk menumbuhkan perlaku ibu-ibu dalam pemeliharaan kesehatan bayi dan balita apabila mendapat dukungan dari pihak puskesmas dan pemerintah kelurahan setempat. 


\section{UCAPAN TERIMA KASIH}

Pada kesempatan ini penulis mengucapkan terimakasih pada rektor Universitas Padjadjaran, dekan Fakultas Keperawatan, Tokoh-tokoh masyarakat dan Ketua RW 18, Lurah Jayawaras, Kepala Puskesmas Haurpanggung dan para stafnya, juga para mahasiswa profesi Fakultas Keperawatan Universitas Padjadjaran, karena atas segala bantuannya, maka artikel PPM ini dapat tersusun, semoga segala kebaikannya mendapat balasan yang setimpal dari Allah S.W.T. aamiin.

\section{DAFTAR PUSTAKA}

(2011). Kader Posyandu dalam Usaha Perbaikian Gizi Keluarga. Jakarta: Departemen Kesehatan RI

(2012). Pemantauan pertumbuhan anak. Jakarta: Direktorat Gizi Masyarakat.

(2016). Status Gizi dan Imunisasi Ibu dan Anak di Indonesia. Jakarta: Departemen Kesehatan RI (2009), Undang-Undang RI No. 36 Th. 2009 Tentang Kesehatan.

Adriani M, Wirjatmadi B (2012). Pengantar Gizi Masyarakat. Jakarta: Prenadamedia Group.

Angelina, R., fauziah, 1., Sinaga, A., Sianipar, I., Musa, E., dan Yuliani, Y. (2020). Peningkatan Kinerja Kader Kesehatan Melalui Pelatihan Kader Posyandu di Desa Babakan Kecamatan Ciparay. JPKMI (Jurnal Pengabdian Kepada Masyarakat Indonesia), 1(2), 68-76. doi: https://doi.org/10.36596/jpkmi.v1i2.30

Dinkes Prop.Jabar. (2015). Profil Kesehatan Propinsi Jawa Barat Tahun 2015. Bandung: Dinkes Prop.Jabar.

Dinkes Kab.Garut (2015). Rencana Strategi Dinas Kesehatan Kabupaten Garut Tahun 2015-2019. Garut: Dinkes Kab.Garut.

Handayani R (2017) Faktor - faktor yang berhubungan dengan status gizi pada anak Balita. Padang

Kemenkes RI. (2015). RPJMN Th. 2015-2019. Jakarta: Kemenkes RI.

Kristanti, L., dan Sebtalesy, C. (2021). Pendidikan Kesehatan Gizi Usia Sekolah sebagai Upaya Peningkatan Prestasi Belajar SDN Purworejo 03 Geger Madiun. JPKMI (Jurnal Pengabdian Kepada Masyarakat Indonesia), 2(1), 57-65. doi: https://doi.org/10.36596/jpkmi.v2i1.123 
Maulana, H.D.J. (2009). Promosi Kesehatan. Cetakan I. Jakarta: EGC

Nurmala, I., Rahman, F., Nugroho, A., Erlyani, N., Laily, N. (2018). Promosi Kesehatan. Surabaya: Airlangga University Press.

Republik Indonesia (2014). Undang-Undang RI No. 35 Th. 2014 Tentang Perubahan Atas Undang-undang No. 23 Tahun 2002 Tentang Perlindungan Anak.

Sefrina, Linda Riski dan Elvandari Milliyantri. (2020). Pelatihan Penilaian Status Gizi pada Guru dalam Rangka Deteksi Siswa Stunting di Sekolah Dasar. Dharmakarya Vol 9 no 1 Hal 4-7. doi: https://doi.org/10.24198/dharmakarya.v9i1.24854 